\title{
Sodium selective erythrocyte glycocalyx and salt sensitivity in man
}

\author{
Hans Oberleithner
}

Received: 3 July 2014 / Accepted: 7 July 2014 /Published online: 17 July 2014

(C) The Author(s) 2014. This article is published with open access at Springerlink.com

\begin{abstract}
Negatively charged surfaces of erythrocytes (RBC) reflect properties of the endothelial glycocalyx. Plasma electrolytes counteract these charges and thus control the repulsive forces between $\mathrm{RBC}$ and endothelium. Although $\mathrm{Na}^{+}$is supposed to exert a rather high affinity to the RBC surface, a direct comparison between $\mathrm{Na}^{+}$and $\mathrm{K}^{+}$in counteracting the RBC surface has been never made. Therefore, we measured $\mathrm{Na}^{+} / \mathrm{K}^{+}$selectivity of the RBC surface in 20 healthy volunteers applying the previously published salt blood test (SBT). It turned out that the $\mathrm{Na}^{+} / \mathrm{K}^{+}$selectivity ratio of the $\mathrm{RBC}$ glycocalyx is on average $6.1 \pm 0.39$ (ranging from 3 to 9 in different individuals). Considering standard plasma $\mathrm{Na}^{+}$and $\mathrm{K}^{+}$concentrations, binding probability of $\mathrm{Na}^{+} / \mathrm{K}^{+}$at the $\mathrm{RBC}$ surface is about $180: 1$. The SBT reveals that plasma $\mathrm{K}^{+}$ counteracts only about $7 \%$ of the negative charges in the $\mathrm{RBC}$ glycocalyx. As an in vivo proof of principle, a volunteer's blood was continuously tested over 6 months while applying a glycocalyx protective polyphenol-rich natural compound (hawthorn extract). It turned out that $\mathrm{RBC} \mathrm{Na}{ }^{+}$ sensitivity (the inverse of $\mathrm{Na}^{+}$buffer capacity) decreased significantly by about $25 \%$ while $\mathrm{Na}^{+} / \mathrm{K}^{+}$selectivity of the RBC glycocalyx declined only slightly by about $8 \%$. Taken together, (i) plasma $\mathrm{Na}^{+}$selectively buffers the negative charges of the $\mathrm{RBC}$ glycocalyx, (ii) the contribution of $\mathrm{K}^{+}$in counteracting these negative surface charges is small, and (iii) natural polyphenols applied in vivo increase RBC surface negativity. In conclusion, low plasma $\mathrm{Na}^{+}$is supposed to favor frictionless RBC-slipping through blood vessels.
\end{abstract}

Keywords Glycocalyx · Sodium sensitivity $\cdot$ Salt blood test . Surface charge $\cdot$ Hawthorn $\cdot$ Polyphenol

H. Oberleithner $(\bowtie)$

Institute of Physiology II, University of Münster, Robert-Koch-Str.

27b, 48149 Münster, Germany

e-mail: oberlei@uni-muenster.de

\section{Introduction}

In humans, one liter of blood contains about one billion erythrocytes (RBC) that usually neither lump together nor attach to blood vessel walls. This impressive phenomenon is explained by the negatively charged (repulsive) surfaces of RBC and vascular endothelium [17, 28]. The surfaces are coated with a gel-like glycocalyx, rich in water and anionic glycosaminoglycans [23, 31]. Surface electronegativity creates so-called zeta potentials that are counteracted by plasma cations $[11,12]$. In this scenario, $\mathrm{Na}^{+}$plays a major role due to its high concentration in the extracellular fluid (e.g., blood), its high affinity to the negatively charged surfaces of RBC and endothelium, and its damaging influence on the glycocalyx at excessive plasma concentrations $[3,18,20]$.

Recently, we described the so-called salt blood test (SBT) that characterizes in quantitative terms the $\mathrm{Na}^{+}$ binding properties of RBC surfaces [21]. Since RBC surfaces "mirror" those of the vascular endothelium, the RBC surfaces reflect, at least to some extent, properties of endothelial surfaces [17]. Since not only plasma $\mathrm{Na}^{+}$but also plasma $\mathrm{K}^{+}$is known to significantly alter vascular endothelial function [19], the question was raised on the role of $\mathrm{K}^{+}$in the generation of the zeta potential and glycocalyx conformation. Therefore, the SBT, aimed to address $\mathrm{Na}^{+}$sensitivity, was expanded including $\mathrm{K}^{+}$as another inorganic cation. In particular, we focused on the selectivity ratio, $\mathrm{Na}^{+} / \mathrm{K}^{+}$, in terms of counteracting the negative RBC surface charges. The latter were evaluated by measuring $\mathrm{RBC}$ sedimentation velocity in different electrolyte solutions. Furthermore, as a proof of principle, we tested whether $\mathrm{Na}^{+} / \mathrm{K}^{+}$ selectivity changes when the $\mathrm{Na}^{+}$buffering capacity at the RBC glycocalyx is increased by polyphenol-rich 
hawthorn extracts. These natural compounds are known to act on the vascular system [2,4], possibly directly on the endothelial glycocalyx [22]. Here, we describe that, in comparison to $\mathrm{K}^{+}$, RBC glycocalyx is highly selective for $\mathrm{Na}^{+}$and that any improvement of the glycocalyx is likely to increase $\mathrm{Na}^{+}$buffering capacity independent of ambient $\mathrm{K}^{+}$.

\section{Methods}

Expanded salt blood test

The SBT has been described in detail previously [21]. The SBT was expanded in a way allowing - in addition to the evaluation of erythrocyte sodium sensitivity (ESS) - measurements of $\mathrm{RBC} \mathrm{Na}{ }^{+} / \mathrm{K}^{+}$selectivity. In short, $4 \mathrm{ml}$ of blood is drawn from volunteers by venous puncture using heparinized monovettes (Sarstedt Company, Sarstedt, Germany). Blood is centrifuged and washed twice in buffered electrolyte solution (in mmol/l: 10 HEPES=4-(2-hydroxyethyl)piperazine-1-ethane sulfonic acid, $140 \mathrm{NaCl}, 5 \mathrm{KCl}, 1 \mathrm{CaCl}_{2}, 1 \mathrm{MgCl}_{2} ; 1 \%$ bovine serum albumin, $\mathrm{pH}$ 7.4). For a single measurement, washed RBC $(50 \mu \mathrm{l})$ are suspended in three Eppendorf vials containing $75 \mu \mathrm{l}$ of either $150 \mathrm{mmol} / \mathrm{l} \mathrm{NaCl}, 125 \mathrm{mmol} / \mathrm{l}$
$\mathrm{NaCl}$, or $125 \mathrm{mmol} / \mathrm{l} \mathrm{KCl}$ (fixed hematocrit 0.4 ). All three solutions contain $3 \%$ dextran (Sigma 44886, MW 70,000 D). In addition, sucrose is added for maintaining constant osmolality as appropriate. Hematocrit capillary tubes (Safecap P752,000 M; length $75 \mathrm{~mm}$; Scholz Company, Neubiberg, Germany) are filled by capillary forces with the respective three RBC suspensions. Hematocrit capillary tubes, closed at the lower end, are put on stands in an upright position (Fig. 1). $\mathrm{RBC}$ sedimentation (i.e., the length of the supernatant) is measured after $60 \mathrm{~min}$. Erythrocyte sodium sensitivity (ESS) of the individual blood samples is calculated as the ratio of the respective supernatant lengths in 150 and $125 \mathrm{mM} \mathrm{Na}^{+}$ (ESS $\left.=L_{150 \mathrm{Na}} / L_{125 \mathrm{Na}}\right) . \mathrm{Na}^{+} / \mathrm{K}^{+}$selectivity is calculated as the ratio $L_{125 \mathrm{Na}} / L_{125 \mathrm{~K}}$. Calculations of the selectivity factor $f_{\mathrm{Na}+}$ $\mathrm{K}_{+}$and $\mathrm{ESS}_{f}$ (ESS modified by $f_{\mathrm{Na}^{+} / \mathrm{K}^{+}}$) are documented in Fig. 1 and illustrated by a representative example.

\section{Hawthorn experiments in vivo}

After a control period of several weeks, a healthy volunteer ingested $450 \mathrm{mg}$ of hawthorn extract (Crataegutt novo ${ }^{\circledR}$ $450 \mathrm{mg}$, Schwabe GmbH, Karlsruhe, Germany) daily. ESS values and $\mathrm{Na}^{+} / \mathrm{K}^{+}$selectivity were evaluated over a period of about 6 months. This experimental series was preceded by a pilot series of similar length but without measuring $\mathrm{Na}^{+} / \mathrm{K}^{+}$

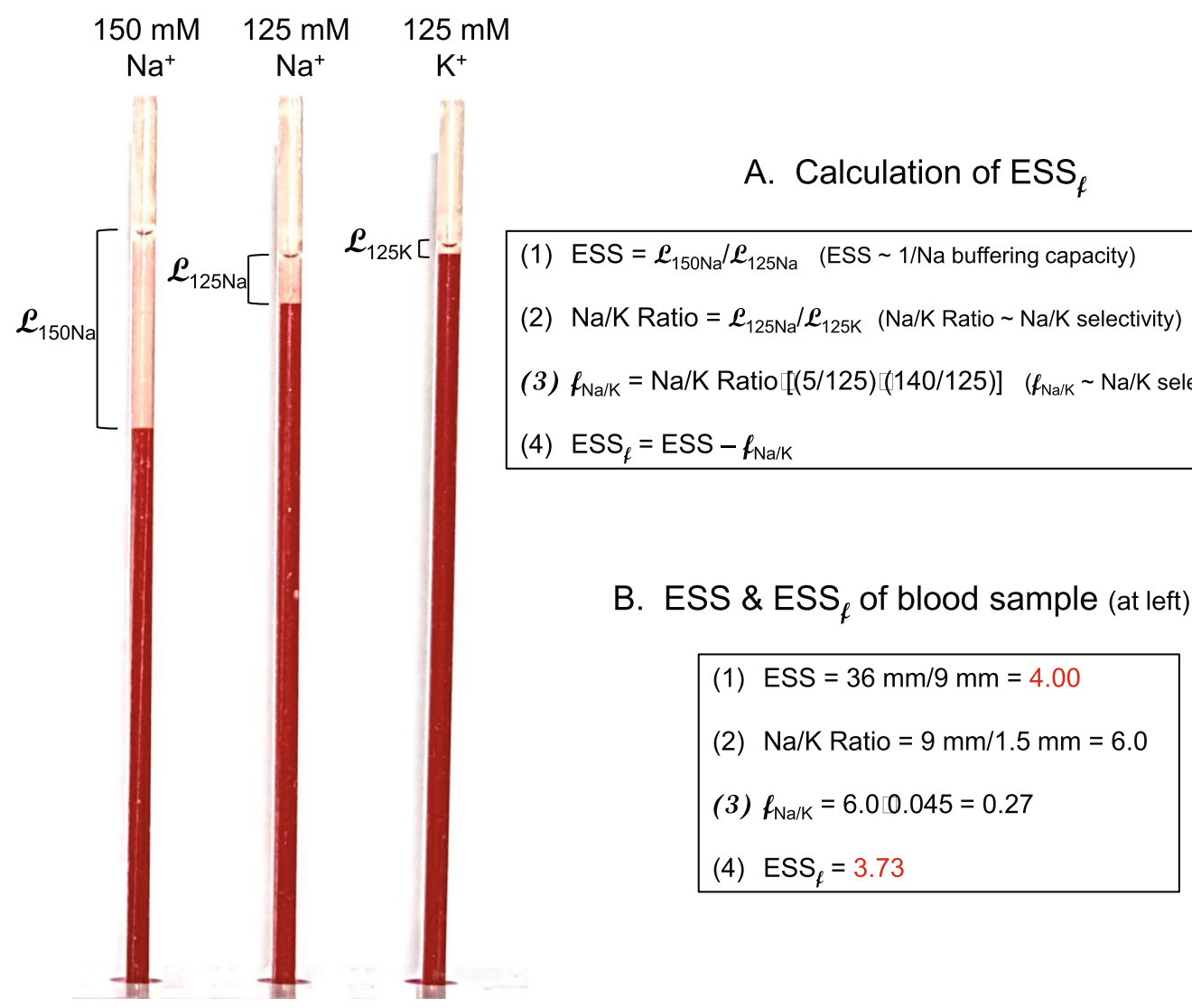

Fig. 1 Salt blood test (SBT) and calculations a leading to ESS (erythrocyte sodium sensitivity), the $\mathrm{Na}^{+} / \mathrm{K}^{+}$selectivity factor $\left(f_{\mathrm{Na}+} / \mathrm{K}^{+}\right)$, and $\mathrm{ESS} f(\mathrm{ESS}-$ $\left.f_{\mathrm{Na}^{+} / \mathrm{K}^{+}}\right)$and $\mathbf{b}$ leading to representative ESS and $\mathrm{ESS}_{f}$ values taken from the three glass capillaries (shown on the left) 
selectivity. Since a clear effect of hawthorn extract on ESS was discovered in this first pilot series (not shown), a fullblown series was started after a break of 3 months (no medication) on which it is reported here. Data in Fig. $4 a-c$ are mean values of at least three measurements of the same blood sample taken at the respective days after start of treatment.

\section{Results}

Figure 1 shows a representative example of a single measurement. From the lengths of the respective supernatants, ESS values and $\mathrm{Na}^{+} / \mathrm{K}^{+}$selectivity ratios are calculated. In order to determine a plasma $\mathrm{Na}^{+} / \mathrm{K}^{+}$selectivity factor $f$ which considers standard plasma $\mathrm{Na}^{+}(140 \mathrm{mmol} / \mathrm{l})$ and $\mathrm{K}^{+}(5 \mathrm{mmol} / \mathrm{l})$, the $\mathrm{Na} / \mathrm{K}$ ratio is modified by relating the
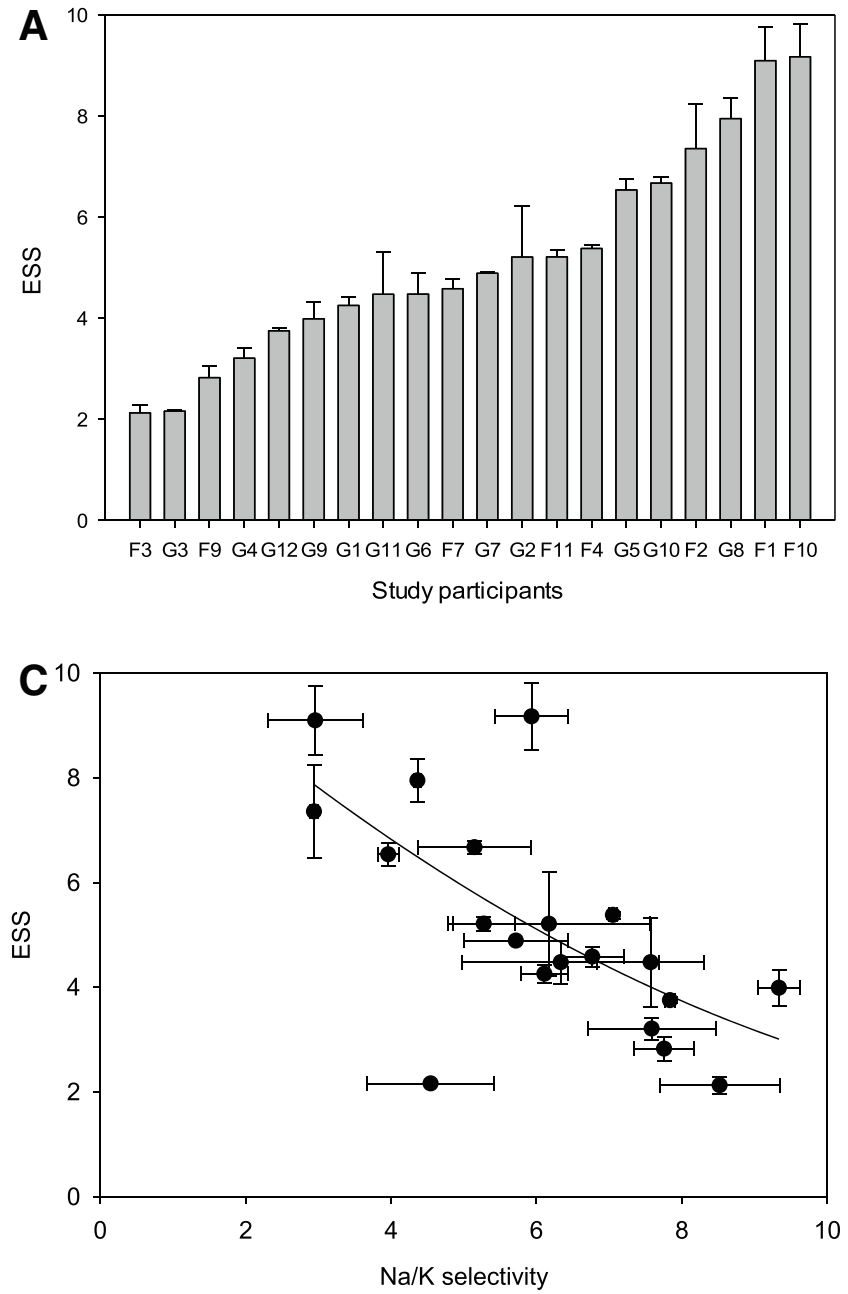

Fig. 2 a Erythrocyte sodium sensitivity (ESS) and $\mathbf{b ~ N a} \mathrm{Na}^{+} / \mathrm{K}^{+}$selectivity of the erythrocyte glycocalyx measured in 20 healthy volunteers (labeled by code numbers). c ESS measured as a function of glycocalyx $\mathrm{Na}^{+} / \mathrm{K}^{+}$ selectivity. The correlation is statistically significant (Spearman correlation coefficient $=0.70 ; p<0.001)$. d Erythrocyte sodium sensitivity experimental $\mathrm{Na}^{+}$and $\mathrm{K}^{+}$concentrations $(150 / 125 \mathrm{mmol} / 1$ $\mathrm{Na}^{+}$and $125 \mathrm{mmol} / 1 \mathrm{~K}^{+}$) to plasma values. As apparent from Fig. 1, the ESS value decreases by only about $7 \%$ when $\mathrm{Na}^{+} / \mathrm{K}^{+}$selectivity is taken into account. Figure $2 \mathrm{a}$ shows ESS values of 20 healthy volunteers (average age $=$ 23 years). Each blood sample was analyzed at least three times. ESS values above 6 indicate a high sodium sensitivity; values below 6 indicate a moderate to low sodium sensitivity. Figure $2 \mathrm{~b}$ displays the $\mathrm{Na}^{+} / \mathrm{K}^{+}$selectivity of the same individuals. On average, the RBC glycocalyx exerts a six times higher affinity to $\mathrm{Na}^{+}$as compared to $\mathrm{K}^{+}$. As indicated in Fig. 2c, there is a significant correlation between ESS and $\mathrm{Na}^{+} / \mathrm{K}^{+}$selectivity. In other words, the RBC glycocalyx of individuals with high $\mathrm{Na}^{+}$sensitivity exerts a low $\mathrm{Na}^{+} / \mathrm{K}^{+}$selectivity and vice versa. By using these $\mathrm{Na}^{+} / \mathrm{K}^{+}$selectivities, modified $\mathrm{ESS}_{f}$ values can be calculated. As shown in Fig. 2d, the $\mathrm{ESS}_{f}$ values
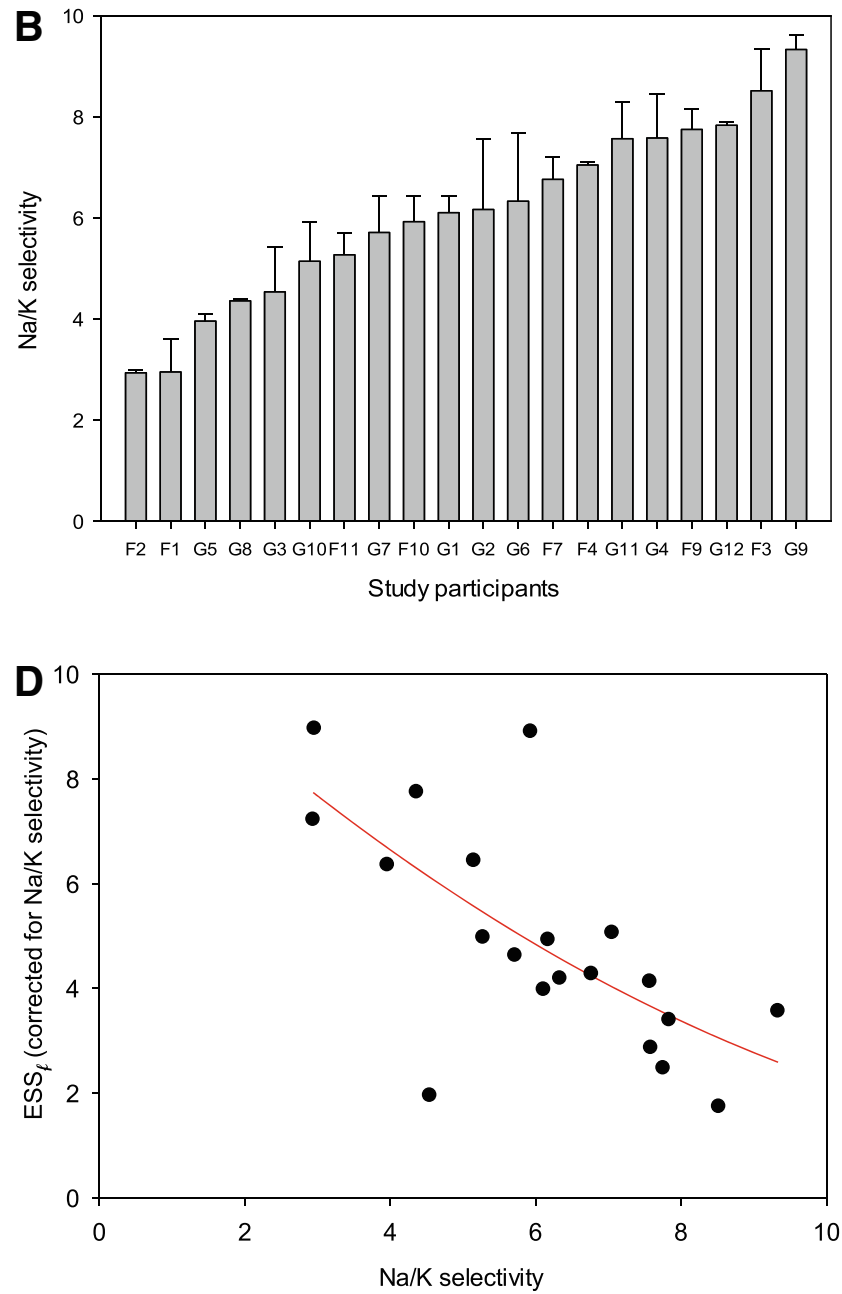

corrected for glycocalyx $\mathrm{Na}^{+} / \mathrm{K}^{+}$selectivity $\left(\mathrm{ESS}_{f}\right)$ measured as a function of $\mathrm{Na}^{+} / \mathrm{K}^{+}$selectivity. The correlation is statistically significant (Spearman correlation coefficient $=0.71 ; p<0.001$ ). In $\mathbf{a}, \mathbf{b}$, and $\mathbf{c}$, mean values of measurements of the same blood sample are given $\pm \operatorname{SEM}(n=\geq 3)$ 
(where $\mathrm{K}^{+}$is taken into account) differ only slightly from the "raw" ESS values (where $\mathrm{K}^{+}$is not taken into account; Fig. 2c). Figure 3 displays the modified $\mathrm{ESS}_{f}$ values which can be compared with the "raw" ESS values shown in Fig. 2a. These values are similar as expected. Taken together, the presence of $\mathrm{K}^{+}$has only little influence on $\mathrm{RBC} \mathrm{Na}^{+}$sensitivity indicating that $\mathrm{Na}^{+}$is the dominating counteracting cation of the negatively charged RBC glycocalyx.

Previous studies indicate that hawthorn extract improves glycocalyx function in vascular endothelium [22] and, in parallel, decreases erythrocyte sodium sensitivity [21]. Since the experiments of the former studies were performed in vitro, it was tempting to test whether hawthorn extract influences ESS in a long-term experiment in vivo and whether there is any change in the $\mathrm{Na}^{+} / \mathrm{K}^{+}$selectivity over time. In a series of experiments, blood of a single healthy individual was continuously analyzed over a period of about 6 months. Figure $4 \mathrm{a}$ shows the ESS values over time. There is a gradual decrease in sodium sensitivity (ESS values) reaching about $25 \%$ after 6 months. At the same time, there is also a minor (statistically not significant; $p=0.35$ ) decrease in $\mathrm{Na}^{+} / \mathrm{K}^{+}$selectivity over time (Fig. 4b). As indicated in Fig. 4c, there is a weak correlation between ESS and $\mathrm{Na}^{+} / \mathrm{K}^{+}$selectivity $(p=0.049)$. When the respective $\mathrm{Na}^{+} / \mathrm{K}^{+}$selectivity values are taken into account, a modified ESS, namely $\mathrm{ESS}_{f}$, can be calculated (Fig. 4d). Comparing the results of Fig. 4a (ESS values versus time) with those of Fig. $4 d$ (ESS $_{f}$ values versus time), it is apparent that the slight decrease of the $\mathrm{Na}^{+} / \mathrm{K}^{+}$selectivity in response to hawthorn treatment does not significantly influence erythrocyte sodium sensitivity. In other words, the polyphenol-rich hawthorn extract improves the RBC glycocalyx $\mathrm{Na}^{+}$buffering power independent of ambient $\mathrm{K}^{+}$.

\section{Discussion}

It was observed previously that the glycocalyx of erythrocytes and vascular endothelium interact with each other [17]. This interaction strongly depends on the negative charges of the glycocalyx [8, 25]. Any loss of negative charge of either endothelium or erythrocytes gradually damages the respective membrane surfaces [18]. These observations led to the development of the SBT aiming to evaluate the erythrocyte surfaces and thus getting insight into the quality of the vascular glycocalyx. The focus is on the interaction of $\mathrm{Na}^{+}$with the erythrocyte surfaces since this ion species is dominating the extracellular fluid including blood, and there is strong evidence in the literature that the $\mathrm{Na}^{+}$affinity of the endothelial glycocalyx is supposed to be high [3, 26]. Furthermore, excessive extracellular $\mathrm{Na}^{+}$concentrations alter endothelial function in terms of reduced nitric oxide release [7] and lead to damages of the endothelial glycocalyx [20]. Since $\mathrm{K}^{+}$is supposed to be a "vascular protective" ion as derived from in vitro experiments [19] and also from clinical studies [1,9], it was of considerable interest to characterize the affinity of $\mathrm{K}^{+}$to the glycocalyx.

The results of the present study show that the affinity of $\mathrm{K}^{+}$ is about six times less than that of $\mathrm{Na}^{+}$, and given the typical plasma concentrations of $\mathrm{Na}^{+}$and $\mathrm{K}^{+}$, the binding probability of $\mathrm{K}^{+}$, or better the probability of $\mathrm{K}^{+}$to counteract the negative charges of the glycocalyx, is only about $0.5 \%$ compared to that of $\mathrm{Na}^{+}$. This indicates that $\mathrm{K}^{+}$does not counteract the negative surface charges to a significant extent indicating that this ion species cannot be made responsible for any significant decreases in RBC zeta potentials and thus will not contribute to enhanced interactions between RBC and vascular endothelium in vivo.
Fig. 3 Erythrocyte sodium sensitivity corrected for $\mathrm{Na}^{+} / \mathrm{K}^{+}$ selectivity $\left(\mathrm{ESS}_{f}\right)$ measured in 20 healthy volunteers (labeled by code numbers). Red columns high sodium sensitivity, green columns low sodium selectivity, and yellow columns moderate sodium sensitivity

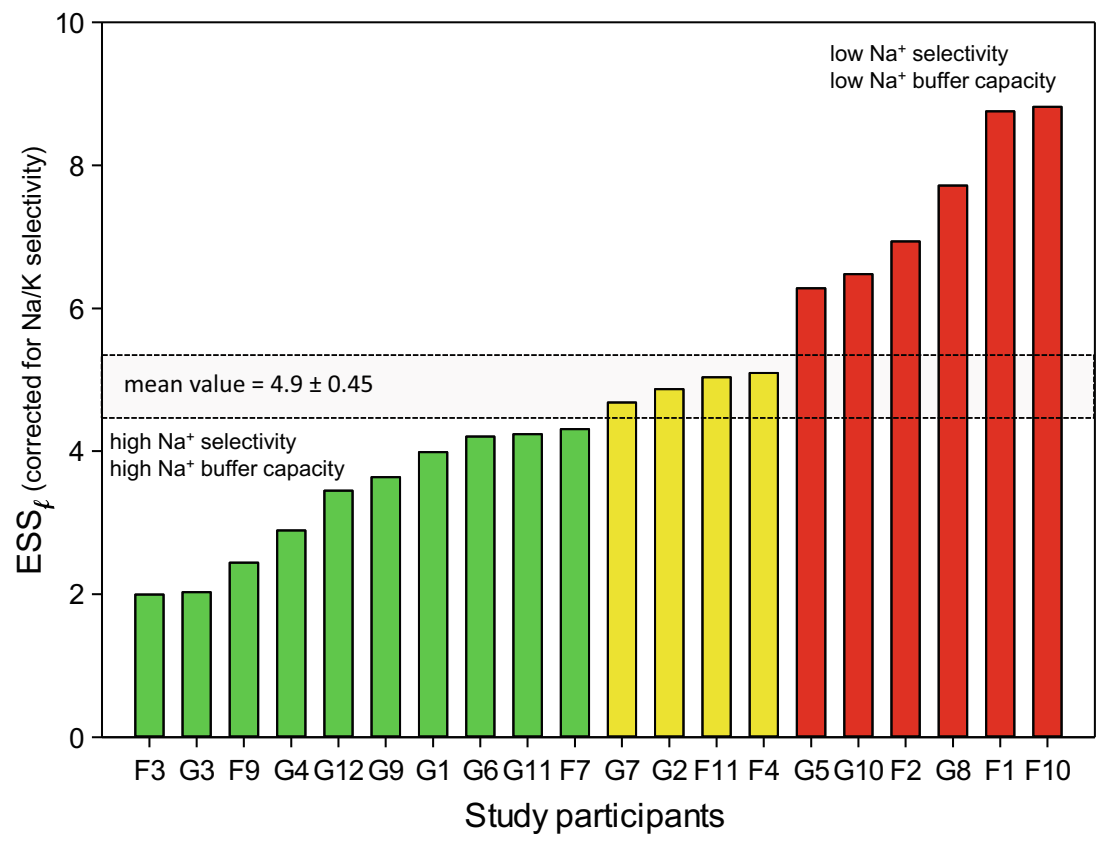



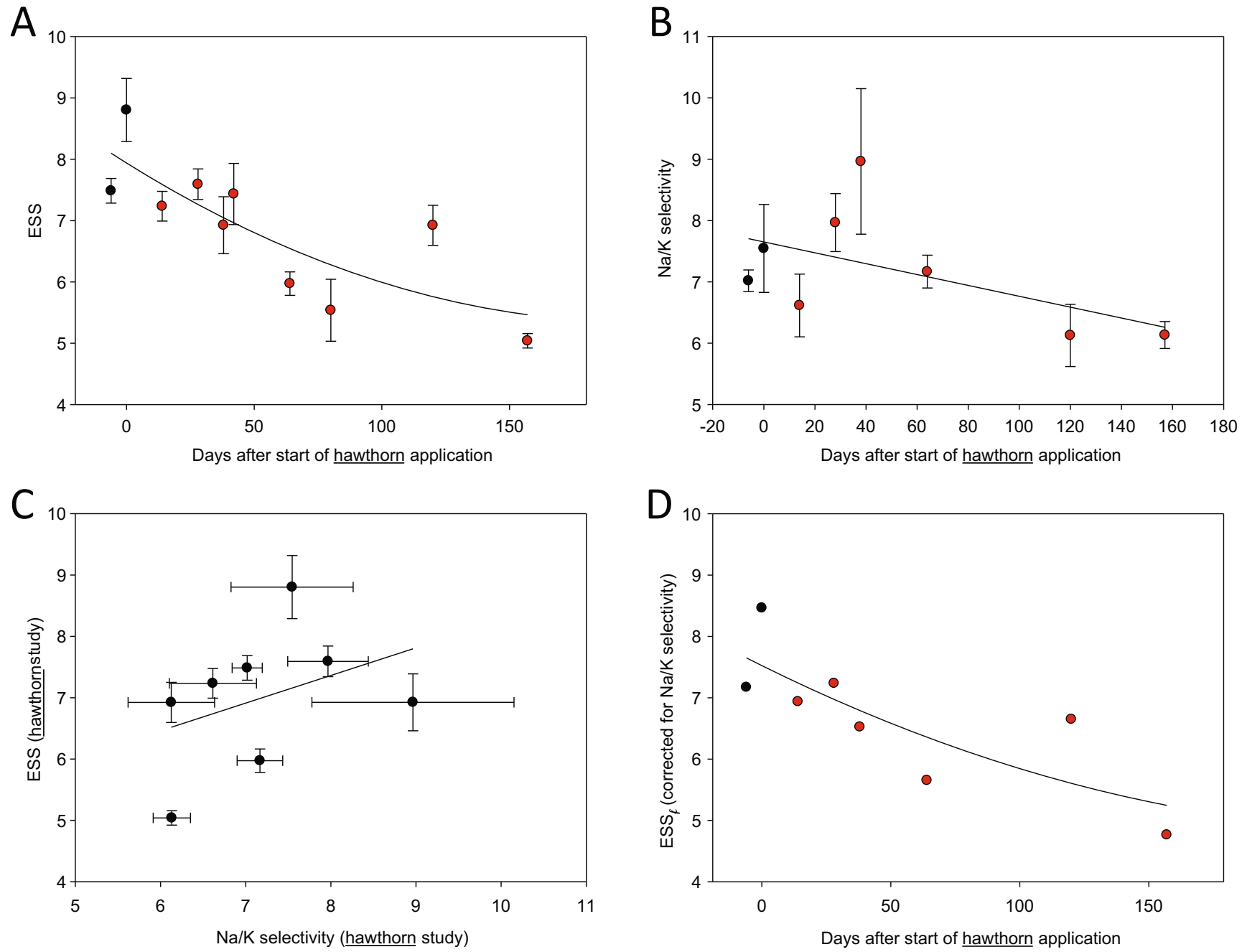

Fig. 4 Data of the hawthorn study. a Erythrocyte sodium sensitivity (ESS) and measured over a total period of about 6 months applying hawthorn extract (oral dose $450 \mathrm{mg} /$ day) in a single individual. The decrease of ESS over time $(\sim 25 \%)$ is statistically significant (Spearman correlation coefficient $=0.85 ; p<0.002)$. b Erythrocyte $\mathrm{Na}^{+} / \mathrm{K}^{+}$selectivity measured over the same time period. The decrease of $\mathrm{Na}^{+} / \mathrm{K}^{+}$selectivity over time $(\sim 13 \%)$ is statistically not significant (Spearman correlation coefficient $=0.38 ; p=0.35$ ). $\mathbf{c}$ ESS measured as a function of glycocalyx

\section{Potential mechanism underlying high glycocalyx $\mathrm{Na}^{+} / \mathrm{K}^{+}$} selectivity

The question arises why $\mathrm{Na}^{+}$interacts so strongly with the $\mathrm{RBC}$ glycocalyx while $\mathrm{K}^{+}$interaction is comparably weak. A similar phenomenon, namely a high $\mathrm{Na}^{+} / \mathrm{K}^{+}$selectivity, has been described for protein surfaces [30]. There, the preference of $\mathrm{Na}^{+}$over $\mathrm{K}^{+}$was explained mainly by cation-specific interactions with the side-chain carboxylate groups of the respective proteins including actin, RNAse, and some others. Obviously, ion specificity originates from local interactions with charged and polar groups at the protein surface [29]. Possibly, a marked difference between $\mathrm{Na}^{+}$ and $\mathrm{K}^{+}$affinities to the glycosaminoglycans of the

$\mathrm{Na}^{+} / \mathrm{K}^{+}$selectivity. The correlation is weak but significant (Spearman correlation coefficient $=0.15 ; p=0.049)$. $\mathbf{d}$ Erythrocyte sodium sensitivity corrected for $\mathrm{Na}^{+} / \mathrm{K}^{+}$selectivity $\left(\mathrm{ESS}_{f}\right)$ measured over time. The decrease (about $27 \%$ ) of $\mathrm{ESS}_{f}$ over time is statistically significant (Spearman correlation coefficient $=0.81 ; p<0.02$ ). In $\mathbf{a}-\mathbf{c}$, mean values of measurements of the same blood sample are given \pm SEM $(n=\geq 3)$. Filled black symbols in $\mathbf{a}, \mathbf{b}$, and $\mathbf{d}$ indicate the control period ( 2 weeks prior to hawthorn application)

glycocalyx lies in the different physicochemistry of the two ion species $[5,6,13,32] \cdot \mathrm{Na}^{+}$is a small ion (radius= $102 \mathrm{pm}$ ) with a surface area of $131 \mathrm{pm}^{2}$. Its relative positive surface charge is 1.06 . Due to its rather high charge density, $\mathrm{Na}^{+}$binds water molecules tightly. $\mathrm{Na}^{+}$ is a marginally kosmotropic ion, a so-called "water structure maker." In contrast, $\mathrm{K}^{+}$is larger compared to sodium (radius $=138 \mathrm{pm}$ ) with a surface area of $239 \mathrm{pm}^{2}$. Its relative positive charge is 0.59 . Due to its rather low charge density, $\mathrm{K}^{+}$binds water molecules weakly, at least compared to $\mathrm{Na}^{+} . \mathrm{K}^{+}$is a weakly chaotropic ion, a socalled "water structure breaker" $[10] . \mathrm{K}^{+}$disturbs hydrogen bounds and the water structure in its vicinity. Relating these ion characteristics to the functional properties of the 
RBC glycocalyx, some assumptions can be made. More than $90 \%$ of the glycocalyx consists of water in which the negatively charged proteoglycans are embedded [24]. Due to the large charge density of $\mathrm{Na}^{+}$, this ion species is preferentially attracted by the glycocalyx surface. In addition, $\mathrm{Na}^{+}$as a "water maker" attracts the polar water molecules to a larger extent as compared to $\mathrm{K}^{+}[10]$. Taken together, $\mathrm{Na}^{+}$in comparison to $\mathrm{K}^{+}$dominates the function of the glycocalyx. In case of excessive plasma $\mathrm{Na}^{+}$, however, the zeta potential decreases under a (still unknown) threshold value leading to enhanced RBC aggregation and endothelial damage $[11,12]$.

In vivo application of Hawthorn extract—a case report

In order to test whether the $\mathrm{RBC} \mathrm{Na}{ }^{+} / \mathrm{K}^{+}$selectivity is altered when changing the glycocalyx properties, an in vivo experiment was performed. Previous studies indicate that polyphenol-rich hawthorn extract improves the nanomechanical glycocalyx of endothelial cells in culture [22]. Furthermore, it was shown in vitro that the interaction between $\mathrm{RBC}$ and endothelium is attenuated by this natural compound [21]. Here, an experimental series (case report) in vivo shows that hawthorn application over a period of 6 months lowers the ESS value indicating a decrease in sodium sensitivity or, in other words, an increase of the glycocalyx $\mathrm{Na}^{+}$buffering power. Obviously, hawthorn extract (i.e., most likely the polyphenols of the extract) leads either to (quantitatively) more negative surface charges and/or to a (qualitative) change in glycocalyx conformation that leads to an improved exposure of the negative charges on the cell surface. Indeed, a better exposure of the anionic viscoelastic biopolymers (glycocalyx) due to shear stress is supposed to preferentially bind $\mathrm{Na}^{+}$on the filamentous glycosylaminoglycans as postulated previously for vascular endothelium [27].

$\mathrm{Na}^{+} / \mathrm{K}^{+}$selectivity slightly decreases along the course of the hawthorn experiment. This small decrease has no strong impact on the ESS values. Taken together, although $\mathrm{Na}^{+} / \mathrm{K}^{+}$ selectivity can vary widely between individuals, between 3 and 9 (this study), it has no considerable influence on glycocalyx $\mathrm{Na}^{+}$buffering power. Improvement of the glycocalyx by applying hawthorn extracts increases the $\mathrm{Na}^{+}$buffering capacity (i.e., decreases the ESS value). Nevertheless, it cannot be excluded that $\mathrm{K}^{+}$interferes significantly with glycocalyx function in certain physiological or pathological conditions. Physical exercise can lead to high local $\mathrm{K}^{+}$concentrations $(\geq 10 \mathrm{mmol} / \mathrm{l})$ in the interstitium of skeletal muscle $[15,16]$. Similar may happen during enhanced activities in limited areas of the central nervous system [14]. Then, $\mathrm{K}^{+}$could increasingly participate in the counteraction of the negative surface charges. The question whether such conditions have any impact on RBC aggregation and RBC-endothelial interaction is still open.
Clinical perspectives and speculations

Negatively charged RBC surfaces attract sodium ions (and water) forming a "safety cushion" between individual RBC but also between RBC and endothelial surface. The ESS value evaluates this cushion. Large ESS values $(>5)$ indicate rather thin cushions; low ESS values $(<5)$ indicate rather thick cushions. Natural polyphenols may thicken (swell) the glycocalyx and thus improve its "cushion" function. A low ESS value indicates "good" $\mathrm{Na}^{+}$buffering power in the blood vessel system. Such an individual is less sensitive to ingested $\mathrm{Na}^{+}$and possibly protected more efficiently against any vascular damage. This assumption, however, needs to be tested in clinical trials.

Acknowledgments This work was supported by the Deutsche Forschungsgemeinschaft (Koselleck grant OB63/18) and Cells-inMotion Cluster of Excellence (EXC 1003-CIM). I gratefully acknowledge the networking activities of the COST action TD1002. I thank Drs. Kristina Kusche-Vihrog, Hermann Schillers, and Wladimir Peters for the helpful discussions during the course of the experiments and Marianne Wilhelmi, Barbara Windoffer, and Sergei Handel for their excellent laboratory work.

Conflict of interest The author declares that he has no conflict of interest. The experimental protocol was approved by the local Ethics Committee (Ärztekammer Westfalen-Lippe, approval number 2012029-f-S).

Open Access This article is distributed under the terms of the Creative Commons Attribution License which permits any use, distribution, and reproduction in any medium, provided the original author(s) and the source are credited.

\section{References}

1. Adrogue HJ, Madias NE (2007) Sodium and potassium in the pathogenesis of hypertension. N Engl J Med 356:1966-1978

2. Anselm E, Socorro VF, Dal-Ros S, Schott C, Bronner C, SchiniKerth VB (2009) Crataegus special extract WS 1442 causes endothelium-dependent relaxation via a redox-sensitive Src- and Akt-dependent activation of endothelial NO synthase but not via activation of estrogen receptors. J Cardiovasc Pharmacol 53:253-260

3. Bevan JA (1993) Flow regulation of vascular tone. Its sensitivity to changes in sodium and calcium. Hypertens 22:273-281

4. Brixius K, Willms S, Napp A, Tossios P, Ladage D, Bloch W, Mehlhorn U, Schwinger RH (2006) Crataegus special extract WS 1442 induces an endothelium-dependent, NO-mediated vasorelaxation via eNOS-phosphorylation at serine 1177. Cardiovasc Drugs Ther 20:177-184

5. Collins KD (1995) Sticky ions in biological systems. Proc Natl Acad Sci U S A 92:5553-5557

6. Collins KD (1997) Charge density-dependent strength of hydration and biological structure. Biophys J 72:65-76

7. Fels J, Oberleithner H, Kusche-Vihrog K (2010) Menage a trois: aldosterone, sodium and nitric oxide in vascular endothelium. Biochim Biophys Acta 1802:1193-1202 
8. Godin C, Caprani A (1996) Interactions of erythrocytes with an artificial wall: influence of the electrical surface charge. Eur Biophys J 25:25-30

9. He FJ, MacGregor GA (2008) Beneficial effects of potassium on human health. Physiol Plant 133:725-735

10. Hribar B, Southall NT, Vlachy V, Dill KA (2002) How ions affect the structure of water. J Am Chem Soc 124:12302-12311

11. Jan KM, Chien S (1973) Influence of the ionic composition of fluid medium on red cell aggregation. J Gen Physiol 61:655-668

12. Jan KM, Chien S (1973) Role of surface electric charge in red blood cell interactions. J Gen Physiol 61:638-654

13. Kiriukhin MY, Collins KD (2002) Dynamic hydration numbers for biologically important ions. Biophys Chem 99:155-168

14. Kofuji P, Newman EA (2004) Potassium buffering in the central nervous system. Neuroscience 129:1045-1056

15. Mohr M, Nordsborg N, Nielsen JJ, Pedersen LD, Fischer C, Krustrup P, Bangsbo J (2004) Potassium kinetics in human muscle interstitium during repeated intense exercise in relation to fatigue. Pflugers Arch 448:452-456

16. Nordsborg N, Mohr M, Pedersen LD, Nielsen JJ, Langberg H, Bangsbo J (2003) Muscle interstitial potassium kinetics during intense exhaustive exercise: effect of previous arm exercise. Am J Physiol Regul Integr Comp Physiol 285:R143-R148

17. Oberleithner H (2013) Vascular endothelium leaves fingerprints on the surface of erythrocytes. Pflugers Arch - Eur J Physiol 465(10): $1451-1458$

18. Oberleithner H (2013) Vascular endothelium: a vulnerable transit zone for merciless sodium. Nephrol Dial Transplant 29:240-246

19. Oberleithner H, Callies C, Kusche-Vihrog K, Schillers H, Shahin V, Riethmuller C, MacGregor GA, de Wardener HE (2009) Potassium softens vascular endothelium and increases nitric oxide release. Proc Natl Acad Sci U S A 106:2829-2834

20. Oberleithner H, Peters W, Kusche-Vihrog K, Korte S, Schillers H, Kliche K, Oberleithner K (2011) Salt overload damages the glycocalyx sodium barrier of vascular endothelium. Pflugers Arch - Eur J Physiol 462:519-528
21. Oberleithner H, Wilhelmi M (2013) Determination of erythrocyte sodium sensitivity in man. Pflugers Arch - Eur J Physiol 465:1459-1466

22. Peters W, Drueppel V, Kusche-Vihrog K, Schubert C, Oberleithner H (2012) Nanomechanics and sodium permeability of endothelial surface layer modulated by hawthorn extract WS 1442. PLoS One 7: e29972

23. Pries AR, Secomb TW, Jacobs H, Sperandio M, Osterloh K, Gaehtgens P (1997) Microvascular blood flow resistance: role of endothelial surface layer. Am J Physiol 273:H2272-H2279

24. Reitsma S, SlaafDW, Vink H, van Zandvoort MA, oude Egbrink MG (2007) The endothelial glycocalyx: composition, functions, and visualization. Pflugers Arch - Eur J Physiol 454:345-359

25. Shiu YT, McIntire LV (2003) In vitro studies of erythrocyte-vascular endothelium interactions. Ann Biomed Eng 31:1299-1313

26. Siegel G, Malmsten M, Klussendorf D, Walter A, Schnalke F, Kauschmann A (1996) Blood-flow sensing by anionic biopolymers. J Auton Nerv Syst 57:207-213

27. Siegel G, Walter A, Kauschmann A, Malmsten M, Buddecke E (1996) Anionic biopolymers as blood flow sensors. Biosens Bioelectron 11:281-294

28. Vink H, Wieringa PA, Spaan JA (1995) Evidence that cell surface charge reduction modifies capillary red cell velocity-flux relationships in hamster cremaster muscle. J Physiol 489(Pt 1):193-201

29. Vrbka L, Jungwirth P, Bauduin P, Touraud D, Kunz W (2006) Specific ion effects at protein surfaces: a molecular dynamics study of bovine pancreatic trypsin inhibitor and horseradish peroxidase in selected salt solutions. J Phys Chem B 110:7036-7043

30. Vrbka L, Vondrasek J, Jagoda-Cwiklik B, Vacha R, Jungwirth P (2006) Quantification and rationalization of the higher affinity of sodium over potassium to protein surfaces. Proc Natl Acad Sci U S A 103:15440-15444

31. Weinbaum S, Tarbell JM, Damiano ER (2007) The structure and function of the endothelial glycocalyx layer. Annu Rev Biomed Eng 9:121-167

32. Zhao YH, Abraham MH, Zissimos AM (2003) Determination of McGowan volumes for ions and correlation with van der Waals volumes. J Chem Inf Comput Sci 43:1848-1854 